\title{
Trayectorias socioeducativas de maestro/as indígenas del centro chaqueño
}

\section{Soledad Aliata}

Facultad de Filosofía y Letras, Universidad de Buenos Aires, Argentina. Profesora y doctora en Ciencias Antropológicas. Becaria posdoctoral CONICET.

(iD) https://orcid.org/oooo-0001-8998-2693

Correo electrónico: soledadaliata@gmail.com
Recibido:

1 de mayo de 2020

Aceptado:

1 de marzo de 2021

doi: 10.34096/runa.v42i2.7480

\section{Resumen}

Este artículo es parte de un trabajo de tesis doctoral en Antropología Social centrado en documentar la diversidad y complejidad en las trayectorias socioeducativas de un grupo de maestros/as indígenas de la provincia del Chaco, Argentina. En este escrito presentaremos algunas de las reflexiones del análisis de los relatos autobiográficos de dos maestros/as indígenas articulando las trayectorias de los sujetos con ciertos procesos de diversidad y desigualdad socioeducativa de la región. Se trata de un primer acercamiento que busca destacar la perspectiva de los/as maestros/as indígenas, reflexionar acerca de distintos aspectos que emparentan y/o diferencian sus relatos y, a su vez, comprender ciertos sucesos sociohistóricos que consideramos fundamentales para avanzar en el estudio de los procesos socioeducativos en contextos interculturales actuales. La metodología se basó en la perspectiva etnográfica en combinación con aportes del recurso metodológico del relato autobiográfico. Efectuamos entrevistas en profundidad, observaciones participantes, charlas informales con agentes educativos y relatos autobiográficos con numerosos/ as docentes qom de la región. Desde una perspectiva crítica, el marco teórico se centra en los estudios que indagan en la figura de los/as maestro/as indígenas, en las trayectorias socioculturales y en los debates en torno a los procesos identitarios. Este enfoque, en articulación con investigaciones acerca de la educación en contextos de diversidad y desigualdad social, busca cuestionar las miradas esencialistas acerca de dichos sujetos.

\section{Palabras clave}

Trayectorias socioeducativas; Maestro/as indigenas; Relatos autobiográficos; Diversidad; Desigualdad 


\section{Socio-educational trajectories of indigenous teachers of the Chaco center}

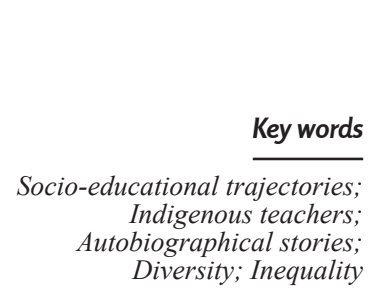
tobiographical stories; Diversity; Inequality

Palavras-chave

Trajetórias socioeducativas; Professores indígenas; Histórias autobiográficas; Diversidade;

Desigualdade

\section{Abstract}

This article is part of the doctoral thesis work in Social Anthropology, focused on documenting the diversity and complexity in the socio-educational trajectories of a group of indigenous teachers in the province of Chaco, Argentina. In this writing we will present some of the reflections of the analysis of the autobiographical accounts of two indigenous teachers articulating the trajectories of the subjects with certain processes of diversity and socio-educational inequality in the region. It is a first approach to analysis that seeks to highlight the perspective of indigenous teachers, reflect on different aspects that relate and / or differentiate their stories and, in turn, understand certain socio-historical events that we consider essential to advance in the analysis of socio-educational processes in current intercultural contexts. The methodology was based on the ethnographic perspective in combination with contributions from the methodological resource of the autobiographical account. We carry out in-depth interviews, participant observations, informal talks with educational agents, and autobiographical accounts with numerous Qom teachers in the region. From a critical perspective, the theoretical framework focuses on studies that investigate the figure of indigenous teachers, sociocultural trajectories, and debates around identity processes. This approach, in conjunction with research on education in contexts of diversity and social inequality, seeks to question essentialist views of indigenous teachers.

\section{Trajetórias socioeducativas de professores indígenas do cen- tro do Chaco}

\section{Resumo}

Este artigo faz parte do trabalho de tese de doutorado em Antropologia Social, focado em documentar a diversidade e a complexidade nas trajetórias socioeducativas de um grupo de professores indígenas da província de Chaco, Argentina. Neste artigo, apresentaremos algumas das reflexões da análise dos relatos autobiográficos de dois professores indígenas articulando as trajetórias das disciplinas com certos processos de diversidade e desigualdade socioeducativa na região. É uma primeira abordagem da análise que busca destacar a perspectiva dos professores indígenas, refletir sobre diferentes aspectos que relacionam e / ou diferenciam suas histórias e, por sua vez, compreender certos eventos sócio-históricos que consideramos essenciais para avançar na a análise de processos socioeducativos nos contextos interculturais atuais. A metodologia foi baseada na perspectiva etnográfica em combinação com contribuições do recurso metodológico do relato autobiográfico. Realizamos entrevistas detalhadas, observações dos participantes, conversas informais com agentes educacionais e relatos autobiográficos com vários professores de Qom na região. Do ponto de vista crítico, o referencial teórico enfoca estudos que investigam a figura de professores indígenas, trajetórias socioculturais e debates sobre processos de identidade. Essa abordagem, em conjunto com a pesquisa sobre educação em contextos de diversidade e desigualdade social, busca questionar visões essencialistas dos professores indígenas. 


\section{Introducción}

A partir del trabajo de análisis desarrollado en la tesis doctoral en Antropología Social finalizada en 2019, en este artículo delinearemos algunas de las reflexiones. El objetivo de la tesis consistió en documentar la diversidad y complejidad de las trayectorias socioeducativas de un grupo de maestros/as indígenas del centro chaqueño, describir el contexto histórico de la región y ahondar en aspectos relativos al rol/formación de estos docentes en contextos de EIB. También, sintetizar sus trayectorias considerando los procesos de articulación/ solapamiento/negación identitaria. El objetivo de este artículo es presentar el análisis de los relatos autobiográficos de dos de ellos, e indagar en sus trayectorias socioeducativas y los procesos de diversidad y desigualdad que se evidencian en los contextos de EIB.

A partir de investigaciones colectivas e individuales previas, pudimos evidenciar que ciertas tensiones y problemáticas socioeducativas estaban vinculadas con la formación de los/as docentes indígenas, el rol en las aulas, etc., y la construcción de sentidos estigmatizantes respecto de lo indígena en el ámbito educativo. Por esa razón, nuestro interés se focalizó en la figura de estos maestros/as.

Por motivos de espacio, no nos detendremos a desarrollar el marco teórico de la investigación en este trabajo. Simplemente, señalaremos que recuperamos las reflexiones de diversas autoras del campo de la Antropología y Educación (Cragnolino, 2002, 2006; Cerletti, 2005; Diez, 2006; Novaro, Borton, Diez y Hecht, 2008; Santillán, 2008, 2011; Gessaghi, 2011), cuyos enfoques consideran dimensiones más extensas y diversificadas de las trayectorias de los sujetos. Es decir, reflexionan sobre la participación de diversos actores, organizaciones sociales y barriales, distintas temporalidades y lugares por los cuales transita una persona, en articulación con los procesos de identificación y los contextos de desigualdad social. A partir de este abordaje, en diálogo con estudios acerca de las identidades (Brubaker y Cooper, 2001; Briones 2002, 2007, entre otros), es posible comprender cómo los sujetos han sido identificados en distintas etapas de la vida por múltiples actores e instituciones, y qué procesos de autoidentificación atravesaron. En ese sentido, creemos que la articulación entre la idea de trayectorias y los procesos de identificación son fundamentales para evidenciar la heterogeneidad que existe en las interacciones sociales, y al mismo tiempo el carácter paradójico y espiralado que encarna la vida de los sujetos. Permite además cuestionar las perspectivas reduccionistas y esencialistas acerca de los/as maestros/as indígenas.

Con respecto al trabajo metodológico de la investigación, este se basó en la perspectiva etnográfica (entrevistas en profundidad, observaciones participantes, charlas informales con maestros/as indígenas y no indígenas, directivos, entre otros). Dado el interés en indagar en la figura de los/as docentes indígenas, incorporamos algunos aportes del recurso metodológico del relato autobiográfico. Esta combinación resulta una herramienta nodal para un acercamiento más detallado de las trayectorias de los sujetos con quienes trabajamos, considerando los contextos históricos en los que están inmersos como grupo social, las particularidades de la región chaqueña y, al mismo tiempo, los recorridos, elecciones y posibilidades de cada sujeto como miembro de una comunidad indígena y como educador. 
1. Según afirman las comunidades, existen 38 pueblos indígenas en todo el país. El Estado lleva el registro de 34 pueblos inscriptos en el Registro Nacional de Comunidades Indígenas ( $\mathrm{ReNaCl}$ ) (Página del Ministerio de Cultura de la Nación https://www.cultura. gob.ar/dia-internacional-de-lospueblos-indigenas_6292/).
Creemos que reflexionar sobre estos ejes puede brindar un gran aporte para pensar la situación actual de los/as maestros/as indígenas y las condiciones socioeducativas de la región.

El trabajo está dividido en cuatro partes. En primer lugar describimos algunas características socioeducativas actuales del pueblo toba/qom en la región. En segundo lugar, nos detendremos a presentar algunas características generales de los/as maestros/as indígenas que realizaron los relatos (Sandra y Gabriel, cuyos nombres son ficticios, para preservar el anonimato) y exponemos ciertas ideas relevantes sobre el trabajo con relatos autobiográficos. En tercer lugar, realizaremos un resumen de cada relato y en cuarto lugar, presentamos algunas reflexiones acerca del análisis de las trayectorias de los sujetos en relación con ciertos procesos de diversidad y desigualdad socioeducativa de la región. Finalmente, esbozaremos algunas reflexiones finales.

\section{Contextualización y escenario socioeducativo actual del pue- blo toba/qom}

Antes de presentar el análisis, señalaremos algunas características que consideramos relevantes sobre el pueblo toba/qom. En primer lugar, es importante aclarar que Argentina se define como país pluriétnico y multilingüe, formado por poblaciones criollas, migrantes (en su gran mayoría de países limítrofes y latinoamericanos) y más de treinta grupos indígenas. ${ }^{1}$ Cuenta con un total de cuarenta millones de habitantes, de los cuales un 2,4\% se define indígena o descendiente de grupos indígenas (INDEC, 2010). De las 955.032 personas indígenas, 126.967 se reconocen como toba/qom, siendo este el segundo grupo indígena más numeroso de nuestro país (UNICEF, 2011). En relación con las lenguas, en diferentes grados de bilingüismo se hablan el español, las lenguas de los países migrantes y catorce lenguas indígenas (Hecht, García Palacios, Enriz y Diez, 2015). Se calcula que el índice de analfabetismo entre quienes se autorreconocen como originarios o descendientes de pueblos originarios es del 3,7\%. A medida que aumenta la edad de la población, el porcentaje de analfabetos es mayor, lo que daría cuenta de un supuesto proceso de inclusión dentro del sistema educativo en décadas más recientes. Sin embargo, existen regiones del país en las cuales la inclusión de las jóvenes generaciones al sistema educativo aún es insuficiente (INDEC, 2010).

En segundo lugar, esta región chaqueña comprende un área urbana habitada principalmente por población no indígena, y una rural, donde viven mayormente familias autoidentificadas como qom, mocoví, wichí y algunas criollas. Esta última es reconocida por tener un nivel menor en cuanto a la calidad educativa respecto de otras zonas vecinas, como así también escasez de recursos económicos y de subsistencia, y una marcada estigmatización en torno a lo indígena. Pueden divisarse extensas zonas de campo y viviendas de adobe, y un acceso limitado a servicios de agua potable, gas, electricidad, entre otros. Actualmente, varios establecimientos educativos del lugar funcionan con modalidad de EIB. Es decir, poseen cargos de maestros/as bilingües interculturales/idóneos/ auxiliares indígenas, según el caso, que ejercen frecuentemente en contextos de diversidad sociocultural y desigualdad social. Ambas regiones se encuentran íntimamente relacionadas por actividades comerciales, laborales y familiares, entre otras. 
En tercer lugar, nos parece necesario mencionar que la provincia del Chaco se destaca por ser pionera en materia legislativa para implementar y reglamentar la educación destinada a pueblos indígenas (EIB). En la actualidad, esto se ve reflejado en numerosas leyes que en los últimos años permiten ir profundizando la modalidad. Por ejemplo, la Ley de Educación del Chaco № 6691 (2010), que ampliará el reconocimiento de la EIB que establecía la ley nacional de 2006 para todos los niveles y modalidades (capítulo XIII); la Ley Provincial de Educación Pública de Gestión Comunitaria Bilingüe Intercultural Indígena № 7446 (2014), que establece que las escuelas de gestión pública comunitaria bilingüe intercultural indígena deben poseer un director/a o vicedirector/a indígena y que por los menos un 50\% del personal del establecimiento debe ser de las comunidades, entre otras. Como señalan Hecht y Zidarich (2016), estos logros son producto de la lucha de los ancianos líderes que impulsaron dichos cambios desde los años 80.

Para finalizar la contextualización, creemos que es importante reconocer que, a pesar de los alcances normativos y legales, estos avances se suscitan en un contexto social, político y económico complejo para la mayor parte de los pueblos indígenas del país. Y puntualmente para las familias autorreconocidas como toba/qom con las cuales trabajamos, que se ven atravesadas por una pronunciada desigualdad socioeducativa. Cuando se analiza lo que ocurre en la franja de jóvenes (de entre quince y diecinueve años), se observa que la tasa de asistencia escolar es significativamente más baja en relación a otras regiones del país. Solo dos de cada cinco adolescentes toba/qom asisten a la escuela. Para la población toba/qom de más de quince años de edad, los datos revelan que casi uno/a de cada cinco miembros del pueblo no ha recibido instrucción formal alguna a lo largo de su vida. Con respecto a los alcances educativos entre quienes alguna vez han asistido a la escuela, el 46,5\% de la población toba no ha logrado completar la escolaridad primaria y tan solo el 32\% la completó (UNICEF, 2011). Es decir, la mayoría de los/as adultos/as mayores toba/qom no han accedido a la escolarización, y aquellos/as que han podido acceder a la escuela, no han logrado finalizar sus estudios, debido, mayormente, a dificultades de índole económica (falta de recursos económicos para la vestimenta o el traslado hacia las escuelas) y sociolingüísticas (niños/as monolingües en su lengua qom que recibían clases solamente en castellano). Las personas que han logrado escolarizarse (en nivel primario y secundario) señalan graves problemáticas de discriminación sufridas por ser indígenas, como por ejemplo: ubicarlos en grados más bajos de los que les correspondía sosteniendo que los/as niños/as indígenas son más "lentos" y menos capaces para el estudio; anular ciertos saberes que traían los/as niños/as a las aulas, como el uso de la lengua indígena, por considerarlos "perjudiciales" para el aprendizaje, entre otros. Una de las principales consecuencias es que se han dejado de transmitir en el seno familiar la lengua qom y aspectos socioculturales propios de la comunidad. A pesar de que hubo un incremento de quienes reciben clases en su lengua nativa, se reconoce que esos datos deben tomarse con precaución, ya que el uso instrumental de la lengua nativa en los contextos escolares no necesariamente implica que los/as niños/as y jóvenes estén siendo alfabetizados en dicha lengua.

Bajo ese panorama complejo y de disputa de intereses disímiles se construye la figura de los/as maestros/as indígenas de la región. Así, ser maestro/a indígena no representa una única forma de pensarse, ni implica una sola manera de autorreconocerse. Más bien se trata de construcciones que se encuentran atravesadas por procesos sociales, políticos y económicos que ponen en tensión, obstaculizan o habilitan ciertos aspectos. 


\section{Vidas contadas}

¿De quiénes hablamos cuando decimos maestros/as indígenas del centro de la provincia de Chaco? ¿Qué representaciones se construyen en torno a dicha figura? ¿Cómo son sus trayectorias en contextos de diversidad y desigualdad social? Lo central de estos interrogantes reside en la posibilidad de lograr un mayor acercamiento a las perspectivas de los sujetos a partir del recurso del relato autobiográfico. Este habilita a problematizar y desnaturalizar determinadas generalizaciones (a veces estigmatizantes y discriminatorias) acerca de la figura del /de la maestro/a indígena. Concretamente, permite reflexionar sobre supuestos y posturas históricamente construidas, que en la actualidad se encuentran vigentes en la cotidianeidad de la vida de los sujetos. Como por ejemplo, una mirada de desconfianza hacia los indígenas, basada en la idea de que tienen menos capacidad que un docente no indígena para ejercer como educadores, capacitadores o directivos, o que poseen una cosmovisión y prácticas que remiten a un atraso para el país (como el hecho de hablar toba/qom). Es interesante que muchos de quienes sostienen estas miradas no mantienen trato frecuente con indígena, pero retoman ideas que circulan en los barrios o en algunos medios de comunicación. En el caso de quienes están vinculados con docentes indígenas y también sostienen estas posturas estigmatizantes, se basan en supuestas experiencias puntuales, pero las generalizan para la totalidad de los grupos indígenas. De allí la importancia de indagar y conocer la vida y formación de estos/as docentes, para evitar reproducir graves estereotipos que minusvaloran ciertos grupos humanos.

Antes de presentar los relatos, nos parece relevante mencionar que un aspecto esencial del relato autobiográfico es que se trata de un "discurso específico otorgador de sentido". En cada entrevista, el sujeto construye una representación de "sí mismo" de su propia identidad como persona. Es un proceso de semantización en el cual las formas de narrar una vida no son azarosas (Piña, 1988, p. 12). En ese sentido, es una interpretación porque implica una elaboración, un modo de expresar cierta mirada. Así, en la entrevista se produce de manera simultánea la interpretación del hablante y la de quien escucha. Otro punto a tener en cuenta es que, de acuerdo con esta metodología, el/la investigador/a debe tratar de intervenir lo menos posible para habilitar que el/la entrevistado/a realice sus propios modos de armar el discurso. Este proceso metodológico permite registrar experiencias respetando las perspectivas y orientaciones del sujeto, y al mismo tiempo aprehender aspectos significativos que surgen en la conformación de los relatos. Sin embargo, no se trata de una posición pasiva de captación y recolección de datos, sino que la entrevista es una situación de investigación conjunta en la cual los significados que surjan serán resultado de ambas intervenciones (Saltalamacchia, Colón y

2. Para profundizar en las reflexiones acerca de las autobiografías en la perspectiva etnográfica, se puede consultar en Aliata, 2020. Rodríguez, 1983, en Aliata, 2020). ${ }^{2}$

De esta manera, vemos que los relatos tienen mucha potencialidad por varios aspectos. Por un lado, permiten visibilizar distintos posicionamientos desde los cuales los/as maestros/as se ubican para relatar sus vidas. En ese sentido, se evidencian posturas de reclamo hacia ciertos hechos, de reivindicación sobre determinados aspectos étnicos y lingüísticos, o formas de valoración hacia espacios educativos y/o diversos sujetos que acompañaron dichas trayectorias. En estas formas de posicionarse, el sujeto construye distintas maneras de representarse e interpretar los sucesos del pasado que brindan información interesante acerca del propio proceso de identificación étnica. Es decir, aquello 
que el sujeto narra es una elección que realiza a lo que le otorga determinado sentido, al exponer aspectos constitutivos de dicho proceso (por ejemplo, el lugar significativo de los estudios terciarios o el rol de acompañamiento y apoyo de algún familiar en un momento de la vida).

Por otro lado, los relatos brindan la posibilidad de reflejar distintas temporalidades y subjetividades de los sujetos, que permiten comprender el carácter dinámico de las identidades (como ser el rechazo, la aceptación y/o la reivindicación de aspectos étnicos y/o lingüísticos que se va transformando en determinados momentos de la vida de la persona). En relación con este punto, un tercer aspecto es la posibilidad que ofrecen los relatos de acceder a distintos trayectos de los sujetos, a los que no podríamos acceder a partir de la observación participante de determinadas experiencias, por ser lejanas en el tiempo. Por ejemplo, los modos en los cuales los sujetos percibían su educación primaria o secundaria, el trato con las familias en la niñez, entre otras. A la vez, entendemos que no es lo mismo vivenciar un hecho que el relato de esa vivencia, ya que este último requiere de una reflexión. O sea, trabajar con relatos evidencia que dichas reflexiones no podrían ser abordadas desde la observación de experiencias directas (por ejemplo, poder conocer qué significó para la persona cursar los estudios terciarios, o asistir a determinada escuela y no a otra). Es decir, posibilita el conocimiento de ciertas realidades e interpretaciones que no podrían conocerse bajo otras formas.

A continuación, describiremos brevemente dos de las autobiografías realizadas. Una perteneciente a Sandra y otra a Gabriel, ambos/as maestros/as indígenas de la región del centro chaqueño. Para el trabajo con los relatos autobiográficos, se buscó realizar una primera entrevista a un grupo de maestros/as $\mathrm{y}$, a partir del análisis, pudimos entrevistar por segunda vez a algunos sujetos, cuyos relatos fueron sugerentes para analizar sus trayectorias socioeducativas en relación con los procesos de autoidentificación e identificación, en contextos de desigualdad y estigmatización. El contacto con los/as entrevistados/as fue posible gracias al vínculo entablado años previos con algunos/as de ellos/ as, quienes nos contactaron con otros colegas. La mayoría de los relatos se realizaron en ambientes cálidos, familiares y cotidianos, ya sea en las propias casas de los sujetos y/o en la casa de algún colega, o en las escuelas donde trabajan diariamente.

Dado el vasto material, la selección de los relatos se realizó considerando la fluidez y el interés del entrevistado/a en compartir saberes y contar su propia historia, y ciertas características de los/as maestros/as del lugar. A diferencia de los adultos mayores, se trata de adultos entre 40 y 50 años que han transitado la escolaridad y han alcanzado estudios terciarios. Además, durante su escolaridad primaria y secundaria no han recibido EIB y recién en los estudios superiores han recibido formación en torno a la interculturalidad y el bilingüismo. Son parte de las primeras camadas de egresados del Centro de Investigación y Formación para la Modalidad Aborigen (CIFMA), instituto de nivel terciario que se encuentra en una localidad aledaña. ${ }^{3} \mathrm{O}$ sea, fueron los primeros en formarse como docentes para dar clases en los establecimientos con modalidad de EIB. Estas características, representativas de un número importante de docentes indígenas de la región, nos parecieron sugerentes al momento de realizar la selección de los sujetos. Asimismo, lo particular de estos relatos es que condensan experiencias y perspectivas que aparecieron en distintas entrevistas, y en ellos es posible evidenciar una sustancial intención en profundizar y visibilizar estas voces.
3. Este instituto es uno de los primeros de la provincia en realizar cursos de capacitación de auxiliares docentes aborígenes. Inicia sus actividades en el año 1987, y posteriormente continuará con la formación de maestros bilingües interculturales y profesores bilingües interculturales. En la actualidad cuenta con otras sedes, y con una Licenciatura de Educación Bilingüe Intercultural. 
4. ENDEPA es un equipo eclesial católico que trabaja con las comunidades indígenas en torno a temas jurídicos, educativos, etc. (Información extraída de http:// www.endepa.org.ar/\#).
Es importante precisar que a partir del análisis no esperamos generalizar la situación de todos/as los/as maestros/as entrevistados/as. Simplemente, pretendemos dar cuenta de ciertos aspectos de las trayectorias socioeducativas que habilitan a pensar desde otro lugar la figura del/a maestro/a indígena y reflexionar sobre el contexto socioeducativo actual.

\section{El relato de Sandra}

Sandra es una mujer de mediana estatura y cabello oscuro. Con tono de voz apaciguado y continuo, suele conversar con rostro sonriente. Nace en el año 1978 en un paraje de la provincia del Chaco. Su padre, por motivos laborales, había viajado y conocido allí a quien luego sería su madre. Luego, la familia se asienta en Colonia Aborigen. A los 17 años se va de la Colonia porque decide estudiar como maestra intercultural bilingüe en el CIFMA, que se encuentra en una localidad chaqueña a $35 \mathrm{~km}$ aproximadamente. En ese momento, un cura párroco -miembro del Equipo Nacional de Pastoral Aborigen (ENDEPA)- ${ }^{4}$ que trabajaba con los jóvenes de la comunidad los incentivó para que estudiaran carreras terciarias. Así, en el año 1995 comenzó a estudiar y, junto con otros jóvenes, conformaron la segunda promoción de maestros/as bilingües interculturales que se recibe en el CIFMA. Sandra expresa que en ese entonces "eran tiempos difíciles", ya que todavía no había cargos para trabajar como docentes bilingües interculturales en las distintas escuelas. No había un planeamiento sistemático de la provincia para lograr la inserción laboral de quienes se recibían en este terciario.

Durante sus años como estudiante, por las mañanas trabajaba haciendo tareas de alfabetización de manera voluntaria con familias qom en Sáenz Peña. El voluntariado, explica, la motivó a cumplir con todas las materias y a tener un gran compromiso con sus estudios. Uno de los recuerdos que menciona como más importantes de esa primera etapa es:

Nunca aprendí la lengua, mi lengua, o sea la lengua materna. Y cuando voy al terciario me encuentro con otra realidad: que todos hablaban su lengua. Los tobas del norte, del sur. Lo mismo los mocoví, los wichí más...Y yo me encontraba como sola. Fui una de las primeras en irme a estudiar, de acá de la comunidad. (Sandra, 2015. Entrevista realizada por Aliata)

Ella, que no es hablante del qom, se relaciona por primera vez con jóvenes de otras comunidades que hablaban la lengua de su pueblo. Ante este suceso, expresa un sentimiento de soledad, ya que no era frecuente salir de la comunidad e ir a estudiar a otro sitio. Ese desafío de viajar sola a otra ciudad y emprender estudios terciarios (experiencia que las generaciones anteriores no habían realizado) la ubicó en una situación diferente con respecto a su familia y a la comunidad. Al mismo tiempo, lo recuerda como una experiencia solitaria por verse diferente a sus compañeros de estudio, que venían de otras trayectorias respecto de la identidad étnica y del uso de la lengua indígena.

Un aspecto nodal en su tránsito por el terciario fue la experiencia que tuvo de "redescubrimiento", ya que ni en la escuela ni en su hogar había hablado de la historia de la familia, ni de la identidad étnica, ni de las lenguas indígenas. Es decir, al interior de su entorno más íntimo señala que nunca hablaban de "ser aborigen, de ser de pueblos originarios, de ser perteneciente a alguna cultura, una lengua... o sea, es algo que se daba nomás... Jamás me senté a reflexionar (se ríe mientras reflexiona)". Es en esa etapa que se encuentra con 
la historia de su familia y con la suya propia. Así lo manifiesta: "Mediante que voy descubriendo la carrera, teníamos que investigar acerca del origen nuestra familia, de dónde provenía todo... Ahí descubro... me descubro yo y descubro la historia de mi mamá y de mis abuelos".

De este modo, Sandra profundiza en sus raíces. Explica que no tiene muchos familiares en la región rural, ya que su bisabuelo del lado paterno era guaraní y llegó al Chaco escapando de la guerra de la Triple Alianza. Recuerda que el hombre cruzó el río nadando y muchos de sus compañeros murieron por las pirañas o porque se los llevaba la correntada. Y al llegar al Chaco, su bisabuelo se refugió entre los toba/qom y en una oportunidad conoció a su bisabuela, que era mocoví. Por parte de su madre, su abuela era vilela y llegó a la región rural porque venían escapando del ingenio azucarero. Si bien en ese trasladarse su familia espera encontrar un lugar más tranquilo, al poco tiempo ocurrió la Masacre de Napalpí. Este acontecimiento fue en 1924, cuando un grupo de indígenas se levantaron en protesta de la explotación y el trabajo forzado impuesto por el gobernador, y el resultado fue el asesinato de cientos de participantes, suceso que afectó y perjudicó profundamente a los habitantes de la región.

En relación con su historia familiar y a sus antepasados guaraníes, vilelas y mocovíes, Sandra expresa "tengo una mezcla (se ríe)... Y después salí yo sin identidad (se ríe)". Una vez transcurrido el período de descubrir la historia de la familia, actualmente atraviesa una etapa en la cual sí hablan de la cultura indígena y la identidad con su familia. El padre empieza a rememorar las historias de sus abuelos y ella siente que sus abuelos también tienen esa apertura, o ella, explica, quizá está más madura como para tener esos diálogos.

\section{El relato de Gabriel}

Gabriel es una persona de aproximadamente cuarenta años, de contextura alta y robusta, de cabellos largos y un modo de hablar pausado. Es docente indígena y pertenece a la comunidad qom. Vive junto a su mujer (profesora intercultural) y su hija en un barrio nuevo de una ciudad del centro chaqueño. Nació en la zona rural, y sus padres aún viven cerca de allí. Ellos no hablan qom, y apenas saben leer y escribir en español algunas palabras. Hace cincuenta años, explica, estaba prohibido hablar en su lengua, y si lo hacían los mataban. Y agrega, "te da una impotencia por lo que pasó, pero te fortalece... uno se pone a pensar el legado que nos dejaron nuestros abuelos [...] de luchar con la palabra, sabiendo que te mataban, porque te asesinaban". Por ello, "los tíos, tatarabuelos sabían muy bien que había que callarse, no hablar en la escuela". (Gabriel, 2015. Entrevista realizada por Aliata)

Durante su niñez, Gabriel cursó en la región rural (primaria y secundaria). Y cuenta que tenía que caminar varios kilómetros para llegar a la escuela. Recuerda que sus maestros/as prácticamente no tenían conocimiento acerca de las comunidades indígenas y, sin conocer el contexto, solían imponer sus ideas. Gabriel tiene una visión crítica de la educación actual y, a pesar de las políticas de EIB, sostiene que aún es necesario seguir trabajando para difundir y capacitar a quienes están involucrados en el ámbito educativo, ya que todavía hay mucho desconocimiento por parte de docentes, directivos y funcionarios sobre las demandas, los saberes y aspectos socioculturales de las comunidades indígenas en las cuales trabajan. 
5. El Instituto de Cultura Popular (INCUPO) es una organización de la sociedad civil de la Región Chaqueña que nace a finales de la década del sesenta, por iniciativa era de un grupo de obispos del nordeste argentino. Su misión inicial fue volcada a la alfabetización de adultos, de acuerdo con el pensamiento del pedagogo Paulo Freire (Información extraída de https://incupo.org.ar/\#)
Sus estudios terciarios los realizó en el CIFMA y recién allí aprendió a hablar la lengua qom, en la materia Cultura e Historia, ya que en su hogar y comunidad no se hablaba en lengua indígena.

Lo que me llevó a estudiar esta profesión como es la docencia es que a través de la misma demanda que presentaban las comunidades que justamente siempre fueron marginadas de la visión occidental o castellano, como quieras llamarlo. [...] Esto nace por la misma demanda de las comunidades. Los mismos padres, tíos, abuelos veían que sus hijos no tenían progreso en educación [...] Una gran problemática era la lengua [...] Generalmente los docentes criollos, como les llamamos nosotros, no están preparados para trabajar en comunidades indígenas [...] se encontraban con otra realidad porque el chico indígena no entendía, por más estrategia, metodología que utilizara ese docente criollo. Él no estaba preparado para enseñar a esos chicos indígenas.Quizás tenía la mejor predisposición pero nunca podía lograr los objetivos [...] Los mismos padres de la comunidad se juntaron con ENDEPA, con INCUPO, para ver qué se podía hacer con la educación indígena [...] La educación indígena nace más o menos en el 86, justamente cuando se sanciona la ley indígena, la 3258. (Gabriel, 2015. Entrevista realizada por Aliata)

Explica que al inicio del CIFMA (1987) había pocos jóvenes con el nivel medio terminado, entonces no podían armar una carrera de nivel superior. Por ello, esos docentes hicieron un doble esfuerzo: primero terminar en un curso acelerado el nivel medio y después capacitarse para trabajar en paralelo con el docente criollo (como ADA-auxiliares docentes aborígenes-). Posteriormente, comenzaron a funcionar otras carreras: profesor bilingüe intercultural y maestro bilingüe intercultural. Los que se formaron en ese momento, como él, tenían el secundario terminado y cuatro años más del CIFMA.

Desde el año 2000 trabaja como maestro intercultural en una escuela de la región rural. Luego comenzó a desarrollar tareas como capacitador de docentes (indígenas y no indígenas) que trabajan en escuelas con EIB, y como profesor de un instituto en una zona aledaña y en la ciudad en la que actualmente vive, en las carreras de Historia y Educación Inicial. Respecto de esos ámbitos, si bien se han abierto a que participe él como miembro de la comunidad, explica que aún se sigue enseñando desde una mirada occidental, o sea, se sigue "integrando al otro" desde la propia lógica no indígena.

En relación con la lengua, Gabriel señala que en su ciudad no se da la enseñanza de la lengua qom. Tanto al interior de las familias como en los ámbitos educativos, no se elaboran espacios para enseñar la lengua. Sostiene que es muy importante la educación indígena y, respecto de los/as maestros/as indígenas, dice que es importante entender que: "la identidad indígena no sea una mochila", refiriéndose a que uno no puede sacársela y ponérsela según le convenga. Gabriel se sigue formando y en la actualidad está cursando la Licenciatura en Educación Intercultural Bilingüe para tener más recursos y posibilidades para trabajar en distintos ámbitos (de enseñanza, gestión, capacitación, etc.). Debido a su participación activa en eventos interculturales y de reclamos de reconocimiento (como por ejemplo, por la Masacre de Napalpí, 12 de Octubre, etc.), es apoyado por algunos colegas pero criticado por otros. 


\section{Trayectorias entrelazadas: diversidad y desigualdad socio- educativa}

Como mencionamos previamente, los relatos seleccionados no solo permiten visibilizar aspectos de las trayectorias socioeducativas particulares de un hombre y de una mujer que se han formado como maestros/as indígenas (con todo lo que ello implica al pertenecer a un grupo social históricamente excluido de la posibilidad de estudiar y tener una profesión), sino que son representativos de un conjunto de maestros y maestras de la región a quienes hemos entrevistado, que han sido de las primeras camadas en salir de la comunidad para emprender estudios terciarios. Es decir, se trata de los primeros grupos que logran traspasar los límites de la escolarización primaria y/o secundaria.

Sus relatos evidencian que muchos/as de los/as docentes indígenas del centro chaqueño han transitado sucesos similares, como fueron los episodios de explotación, violencia y exterminio de muchos de sus antepasados, el temor de sus familias de transmitir la lengua indígena, las experiencias escolares propias de discriminación y las experiencias educativas de reivindicación y revalorización étnica y lingüística durante los estudios terciarios, entre otros. Creemos que en las peculiaridades de cada uno, así también como en las experiencias comunes y compartidas, reside la riqueza de estos relatos. La sistematización y el análisis de estos brindan una herramienta más para visibilizar y comprender otras formas posibles de experimentar y reconocerse como maestro/a indígena en la región. Como señala de Sousa Santos, "la lucha por la igualdad no puede estar separada de la lucha por el reconocimiento de la diferencia" (Sousa Santos, 2010, p. 18). Esperamos a continuación realizar algunas reflexiones en esa dirección.

En primer lugar, un aspecto que consideramos relevante es analizar cómo la idea del pasado que emerge de ambos relatos aparece asociada a cierto período de discriminación, hostigamiento y exterminio de las comunidades indígenas. Tanto Sandra como Gabriel exhiben ciertos sucesos en la historia de su comunidad, que marcaron sus trayectorias. Nos referimos al período de la conformación del Estado nación argentino, que, como señala Achilli (2003), se caracterizó por la "pacificaciones militares" y la construcción ideológica de una argentinidad en la que estos grupos fueron neutralizados. Recordemos que entre finales del siglo XIX y principios del XX, las comunidades indígenas fueron en su mayoría exterminadas y/o arrinconadas en las áreas del país menos productivas. Estos procesos, que afectaron a miles de personas, generaron en el pueblo qom del Chaco drásticas transformaciones en su organización social, ya que muchos/as debieron dejar las tierras productivas (para la caza y recolección) e incorporarse a un sistema de explotación como mano de obra temporaria. Retomar ciertas condiciones sociohistóricas nos resulta medular, ya que, como bien explica Achilli, todas estas situaciones son "prolongaciones de las violencias sufridas desde el siglo XVI en las que les fueron arrebatando sus tierras y enajenándolos de sus propios modos de vida" (Achilli, 2003, p. 292).

En la región que estudiamos, estos sucesos se ven reflejados, por ejemplo, en la Matanza de Napalpí (1924) y en la estigmatización hacia la figura del indígena plasmada en los procesos de castellanización en las escuelas de la zona. Este momento es visto como una etapa en la cual, por temor y/o vergüenza, se ocultaba todo lo referido a cuestiones étnicas. Es decir, al interior de la familia y en la escuela no se mencionaba la pertenencia a una comunidad indígena, tampoco se hablaba la lengua, ni de la historia de la comunidad indígena. Como explica Sandra, "es algo que se daba nomás": ni en la escuela ni al 
interior de las familias se reflexionaba sobre aspectos socioculturales vinculados a lo indígena. En ese período, menciona Sandra, se tenía que "renunciar" a la familia, a las raíces, para tener una profesión, porque si mencionabas que eras perteneciente a una comunidad indígena tenías menos posibilidad de conseguir trabajo o realizar estudios terciarios debido a la gran discriminación. Por eso, señala, muchos se fueron de la comunidad y "no volvieron más". En esta misma dirección, Gabriel expresa la impotencia que le da saber que en ese momento histórico "te mataban" por ser indígena. Pero a su vez, remarca que dichos sucesos también lo fortalecieron, ya que recuerda con orgullo el legado de lucha que dejaron sus abuelos, a pesar de que sufrían graves situaciones de agresión por ser miembros de comunidades indígenas.

Creemos que estos contextos sociohistóricos han dejado una impronta profun$\mathrm{da}$, que se ve reflejada en ambos relatos. Por ejemplo, vemos en las palabras de Sandra cierto impedimento de reconocerse como indígena, que experimenta durante su infancia y juventud debido a estos sucesos. Como señala Czarny para el caso mexicano (2007), se trata escenarios de silenciamientos y negación de pertenencias comunitarias bajo la idea de una sola identidad nacional, que han repercutido, como veremos a continuación, en la escolaridad de los sujetos y han generado accesos desiguales de los grupos indígenas a la escolaridad.

En segundo lugar, vemos que tanto en la trayectoria de Sandra como en la de Gabriel se evidencia una ausencia en la transmisión de saberes vinculados con aspectos socioculturales e históricos de la comunidad durante la niñez y juventud. Si bien, como mencionamos previamente, las políticas en torno a la EIB se vienen gestionando desde hace más de 30 años, su implementación ha sido gradual y despareja en distintas zonas del país. Tanto en el caso de Gabriel como en el de Sandra (referidas a la región del centro chaqueño), se muestra un período en el cual transitaron la escolaridad primaria y secundaria sin una implementación de educación intercultural. Gabriel recuerda las dificultades que tuvo cuando iba a la escuela tanto por la situación de desventaja en la cual se encontraban por vivir en la colonia (tenía que recorrer largas distancias para llegar) como por el trato "conflictivo" o ciertas tensiones que existían entre la mayoría de los/as docentes (no indígenas) y los niños y familias indígenas. Este desconocimiento de parte de docentes y directivos no indígenas acerca de las comunidades con las cuales trabajan cotidianamente llevó, según Gabriel, a que no se respetaran las necesidades y la cosmovisión de estos grupos, y a que se generaran situaciones educativas cotidianas en las cuales, los docentes "solían imponer sus ideas". En ese sentido, Sandra atraviesa también un período en su niñez y juventud carente de formación intercultural bilingüe. Ni al interior de su familia ni en la escuela circulaban saberes en torno a la pertenencia étnica.

Es importante mencionar que, si bien algunas regiones se caracterizaron por la ausencia de políticas estatales educativas destinadas a los pueblos indígenas, son interesantes los análisis de algunos autores como Enriz, García Palacios y Hecht (2016), que hablan de una educación intercultural que antecede a las políticas de Estado. O sea, formas socioeducativas aplicadas en contextos interculturales asociadas a otros movimientos (religiosos, ONG, etc.), y en algunos casos, como el religioso, tuvieron gran influencia en la escritura del qom y en las primeras traducciones de la Biblia que fueron parte de los procesos de evangelización hacia estos pueblos indígenas.

En tercer lugar, un punto relevante en las trayectorias de los/as maestros/as es el reconocimiento de personas no indígenas que han trabajado en la región y que apoyan las demandas de las comunidades y estimulan a muchos jóvenes a 
continuar los estudios terciarios, como algunos movimientos y organizaciones religiosas. Se menciona que algunos grupos religiosos en diferentes momentos históricos han apoyado la escolarización de indígenas por medio de sistemas becas. En el caso de Sandra, ella enfatiza el rol relevante que tuvieron estos movimientos, que desarrollaron un trabajo de enseñanza en oficios y apoyo a los jóvenes de la comunidad para que accedieran a la formación superior.

En cuarto lugar, otro de los aspectos que nos interesa destacar es la transformación en las trayectorias que se evidencia en torno al uso de la lengua y la revalorización sociocultural del pueblo qom. De la mano de las políticas socioeducativas neoliberales se establece una idea de progreso y sociedad que no es compatible con los modos socioculturales que históricamente han construido las comunidades indígenas. Bajo este paradigma, la diversidad cultural y lingüística es puesta en cuestión. En el caso de Sandra, ella resalta el hecho de que durante su niñez y juventud nunca se habló la lengua indígena en su familia. En ese entonces, señala, la lengua indígena era vista como un obstáculo, por eso muchos padres y abuelos dejaron de transmitir la lengua qom a los niños y niñas en pos de "progresar" (es decir, poder acceder a la escuela, conseguir trabajo, etc.). Principalmente, porque en ese momento aún no había maestros/as bilingües y en la escuela solamente se hablaba castellano.

Vemos que tanto en el relato de Sandra como en el de Gabriel hay un punto de quiebre respecto del aprendizaje y significado de la lengua indígena. $\mathrm{O}$ sea, se habla de una etapa en la cual dejar de transmitir la lengua qom significó, para muchas familias, ayudar a los niños/as y jóvenes indígenas a comunicarse y lograr participar también de espacios como el escolar, en el que solamente se podía hablar en castellano. En ese período, lejos de ser un recurso valorado, la lengua indígena adquirió un sentido despectivo y estigmatizante, como un aspecto limitante al desarrollo de los sujetos. Asimismo, muchos grupos indígenas que sufrieron la persecución decidieron dejar de hablar la lengua indígena por vergüenza y/o temor a ser asesinados como ocurrió en la Matanza de Napalpí. El sentimiento de temor y el deseo de que las futuras generaciones no padezcan los mismos problemas de persecución y violencia sistemática que tuvieron que afrontar muchas familias indígenas llevó en muchos casos a evitar hablar en qom y así "resguardar" a los niños/as y jóvenes del peligro. Esta forma de "negación" de la lengua indígena por temor -o para no "entorpecer" el aprendizaje de los/as niños/as que se realizaba en castellano- refleja en la actualidad un escenario en el cual varios grupos indígenas de la región han dejado de comunicarse en dicha lengua. Es decir, en esta región es evidente el desplazamiento de la lengua toba por el español como medio de comunicación familiar y comunitario entre familias que se identifican como indígenas.

Sin embargo, posteriormente se habla de otra etapa, el momento de los estudios terciarios. Allí, los sentidos en torno a la lengua indígena toman otros significados, ya que tanto ésta como la comunidad indígena son revalorizados, y comienza un proceso de enseñanza-aprendizaje enfocado desde una perspectiva de educación intercultural bilingüe. Es significativo cómo este período marcó las configuraciones identitarias de los sujetos, quienes, como Sandra, afirman que "Ahí [en el terciario] descubro... me descubro yo y descubro la historia de mi mamá y de mis abuelos". Concretamente, ella, al transitar los estudios terciarios, se encuentra con "otra realidad: que todos hablaban su lengua". Muchos de los jóvenes que iban a estudiar como ella provenían de regiones en las cuales sí habían recibido enseñanzas propias de sus comunidades (sobre la historia, la lengua, etc.). Lo cual marcó una diferencia con su situación, ya que ella ni hablaba su lengua indígena ni había recibido enseñanzas 
respecto de su comunidad. También Gabriel expone que es recién en el transcurso de sus estudios terciarios que comienza a aprender la lengua qom. En ese espacio socioeducativo, las experiencias diversas en torno a la historia de la comunidad y al aprendizaje de las lenguas indígenas generaron ciertos interrogantes en jóvenes como nuestros dos entrevistados. Así, en el relato de ella se expresa el asombro al conocer compañeros que hablaban la lengua de sus comunidades y, al mismo tiempo, un gran interés en comenzar a conocer y aprender acerca de la suya.

El cambio reflejado en las posturas de Sandra y Gabriel respecto de la transmisión y uso de la lengua qom -que pasa de contener una fuerte carga valorativa negativa a una valoración positiva y de reivindicación- es nodal para comprender los procesos de autoidentificación étnica que abarca nuestra investigación. Estas posturas, que parecen contrapuestas, tienen que ver con las transformaciones en los sentidos respecto de lo indígena, que permea las trayectorias de los sujetos y los modos en que configuran sus identificaciones étnicas.

Un último punto que nos parece relevante mencionar tiene que ver con el escenario actual que perciben los/as maestros/as. En particular, Sandra expone que en el presente atraviesa un período en el que sí se habla al interior de la familia sobre la lengua y la historia de su comunidad. Destaca que tanto su padre como sus abuelos rememoran historias y hay una apertura para estos temas que antes no había. Y al mismo tiempo, esa apertura también la reconoce en ella misma para emprender esos diálogos e indagar en los saberes de su comunidad. Es importante aclarar que, si bien se percibe una atmósfera respecto de la revitalización lingüística de sus comunidades que tiende a ser más favorable, una particularidad del relato de Gabriel es la visibilización de una problemática actual. El maestro expresa que, aunque se ha avanzado en la transmisión de la lengua qom, en esta región del centro chaqueño aún no están dadas las condiciones sociales ni materiales ni se han generado los espacios suficientes para desarrollar la enseñanza de la lengua qom para todos/as los/ as niños/as, jóvenes y adultos/as que la demanden. Si bien en este trabajo no nos vamos a detener en indagar los aspectos estrictamente sociolingüísticos de la región, creemos importante mencionar que, pese a los procesos de castellanización y homogeneización, en el Chaco existe una amplia diversidad y vitalidad lingüística, y en materia de derechos indígenas, se ha alcanzado un gran avance. Sin embargo, en algunas regiones, como la de esta investigación, la mayor parte de sus habitantes no hablan la lengua qom. Esta forma desigual en la que se ha desarrollado la utilización de la lengua indígena al interior de la comunidad genera múltiples condiciones sociolingüísticas (que vacilan entre mayor utilización y transmisión de la lengua vernácula en algunos casos, y mayor vitalidad de la lengua española en otros).

\section{Reflexiones finales}

Dado que este trabajo forma parte de una investigación más amplia, las reflexiones aquí expuestas son un primer acercamiento al análisis de las trayectorias socioeducativas de un grupo de maestros/as indígenas de la provincia del Chaco, con quienes hemos trabajado durante el doctorado. Centralmente, indagamos en los relatos de dos docentes indígenas, articulando algunos ejes que consideramos relevantes de la contextualización de la región, con las trayectorias de los sujetos en torno a procesos de diversidad y desigualdad socioeducativa. Para ello, comenzamos por describir brevemente algunas características socioeducativas actuales; luego presentamos a los entrevistados/as 
y mencionamos algunos ejes interesantes acerca del trabajo con relatos autobiográficos; seguimos con la exposición de los mismos y finalmente, trazamos ciertas ideas alcanzadas a partir del análisis.

Como ya señalamos, abordamos los relatos de un maestro y una maestra, ambos de la comunidad qom, que durante su escolaridad primaria y secundaria no han recibido EIB y recién en el nivel terciario han tenido formación entorno a la interculturalidad y bilingüismo. Asimismo, son los primeros en formarse como docentes para luego dar clases en los establecimientos con modalidad de EIB. A partir del análisis de ambos relatos se evidenciaron, por un lado, la idea de un pasado asociado a la discriminación, exterminio y explotación de las comunidades indígenas. Por otro, también tienen en común la ausencia, durante la niñez y juventud, de saberes y aspectos de la comunidad indígena y la diversidad étnica. Como tercer punto, ambos relatos hablan de ciertos cambios vivenciados en torno a la transmisión y revalorización de la lengua qom y aspectos socioculturales de la comunidad. Asimismo, éstos nos muestran también algunas particularidades, por ejemplo, el reconocimiento de distintos grupos no indígenas que, en un momento determinado, en la región, apoyaron e incentivaron a los jóvenes indígenas a continuar con los estudios terciarios. Todos estos procesos permearon las trayectorias socioeducativas y dan cuenta de ciertas situaciones y experiencias que caracterizan a este grupo de maestro/as.

De esta manera, este primer análisis nos permite comprender un poco más el escenario complejo y particular que atravesaron dichos sujetos. Por una parte, la perspectiva de los propios maestros/as habilita a cuestionar ciertas miradas estáticas y estigmatizantes que hemos podido relevar a lo largo de estos años de investigación en la zona. Nos referimos a las posturas (como por ejemplo, de agentes educativos como supervisores, maestros no indígenas, funcionarios, entre otros) que encasillan a las comunidades indígenas -y a los maestros/as en particular-como sujetos cristalizados en sus experiencias y pensamientos, y con ciertos atributos esenciales y eternos que los definirían como tales. Por ejemplo, sostener que, al no hablar más la lengua indígena, ya no existen indígenas en la región, o determinar que no es posible ser maestro indígena y no hablar en lengua qom, entre otros supuestos. En las narraciones se evidencia que hablar o no la lengua indígena no sería una marca que definiría a una persona como indígena o no, sino más bien tiene que ver con procesos sociales más complejos y dinámicos. En futuros trabajos, expondremos la segunda parte de la tesis, que justamente profundiza sobre los procesos de identificación y autoidentificación étnica de los/as maestros indígenas del centro chaqueño.

Por otra parte, volviendo a lo expuesto en este artículo, dichas trayectorias socioeducativas nos permiten conocer distintas formas de pensarse como docente indígena en contextos de marcada desigualdad social y educativa. También, habilitan a comprender no solo las trayectorias de Sandra y Gabriel, sino ciertos procesos sociohistóricos y educativos de la región, y reflexionar sobre algunas condiciones socioeducativas actuales en las cuales dichos sujetos se encuentran involucrados/as. Al mismo tiempo, estas otras formas de ser maestro/a indígena dan cuenta de la heterogeneidad al interior de un grupo de maestros/as, y pone en cuestionamiento las posturas que encasillan y estigmatizan a la formación, la tarea o el rol de los mismos como acciones devaluadas o valoradas negativamente. Generalmente, estas miradas se basan en ideas etnocéntricas de acuerdo con las cuales estas personas se encuentran atrasadas socioculturalemente y cuyos modos de vida y pensamiento terminarían perjudicando la educación y las condiciones generales del país. 
Para terminar, consideramos importante poder indagar en los relatos autobiográficos de dichos sujetos, ya que así no solo se visibiliza una problemática en el ámbito educativo, sino que nos ayuda a pensar también acerca de los modos sutiles de dominación que se perpetuán en el tiempo a partir de reproducir formas esencialistas y cosificantes sobre las identidades de ciertos grupos, que parecen agravarse en los contextos sociales y políticos nacionales e internacionales que vivimos actualmente. Creemos que reflexionar sobre estos supuestos puede ser un pequeño aporte para poner en cuestión discursos estigmatizantes fuertemente difundidos, no solo en el campo educativo, sino también en los medios masivos de comunicación y en las redes sociales, entre otros.

\section{Agradecimientos}

Agradezco a todas las personas que me brindaron su tiempo y confianza para realizar el trabajo en una zona del centro de Chaco, y principalmente a Sandra y Gabriel (nombres ficticios) por compartir sus experiencias. 


\section{Q Referencias bibliográficas}

》Achilli, E. (2003). Escuela, Familia y Etnicidades: Investigación Socioantropológica en Contextos Interculturales de Pobreza Urbana (tesis de doctorado). Facultad de Filosofía y Letras, Universidad de Buenos Aires, Argentina.

"Aliata, S. (2020). Método autobiográfico para el estudio de procesos identitarios y trayectorias socioeducativas. Revista del CISEN Tramas/Maepova, 8(1), 23-33. Recuperado de http://ppct.caicyt.gov.ar/index.php/cisen/index

" Briones, C. (2002). Mestizaje y blanqueamiento como coordenadas de aboriginalidad y nación argentina. Runa, 23, 61-88.

"Briones, C. (2007). Teorías performativas de la identidad y performatividad de las teorías. Tabula Rasa, 6, 55-83.

"Brubaker, R. y Cooper, F. (2001). Más allá de “identidad”. Apuntes de Investigación del CECYP, 7, 30-67.

"Cerletti, L. (2005). Familias y educación: prácticas y representaciones en torno a la escolarización de los niños. Cuadernos de Antropología Social, 22, pp. 173-188. http://revistascientificas.filo.uba.ar/index.php/CAS/article/view/4434/3937

»Cragnolino, E. (2002). Trayectorias educativas en familias de origen campesino del Norte cordobés. Cuadernos de Educación. La Educación como espacio público: Historia, políticas y escenarios cotidianos, 2, 151-165.

"Cragnolino, E. (2006). Trayectorias sociales y apropiación de la cultura escrita en un grupo de mujeres de Córdoba. VIII Congreso Argentino de Antropología Social, Salta.

"Czarny G. (2007). Pasar por la escuela. Metáfora que guarda distintas caras para abordar la relación comunidades indígenas y escolaridad. Revista Mexicana de Investigación Educativa, RMIE, 12(34), 921-950.

»Diez, M. L. (2006). Las concepciones de los alumnos migrantes en contextos escolares interculturales. Trayectorias de vida marcadas por la migración. XI Simposio Interamericano de Investigación Etnográfica en Educación, SEANSO / ICA -FFyL- UBA. https:// www.academia.edu/33356429/Las_concepciones_de_los_alumnos_migrantes_en_contextos_interculturales_marc3ada_laura_diez

»Enriz, N., García Palacios, M. y Hecht A. C. (2016). Llevar la palabra. Un análisis de la relación entre las iglesias y la escolarización de niños indígenas toba/qom y mbya-guaraní de Argentina. Universitas Humanística, 83, 187-212.

» Gessaghi, V. (2011). Trayectorias educativas y ćlase alta': etnografía de una relación (tesis de doctorado), Facultad de Filosofía y Letras, Universidad de Buenos Aires, Argentina.

" Hecht, A. C., García Palacios, M., Enriz, N. y Diez, M. L. (2015). Interculturalidad y educación en la Argentina. Discusiones en torno a un concepto polisémico (pp. 43-63). En G. Novaro, A. Padawer, A. C. Hecht (coords.), Educación, pueblos indígenas y migrantes: reflexiones desde México, Brasil, Bolivia, Argentina y España. Ciudad Autónoma de Buenos Aires: Biblos.

» Hecht, A. C. y Zidarich, M. (2016). Educación Intercultural Bilingüe en Chaco: Toba/qom y Wichí. En Pueblos indígenas en la Argentina. Ciudad Autónoma de Buenos Aires: Ministerio de Educación y Deportes de la Nación.

» Novaro, G., Borton, A., Diez, M. L. y Hecht, A. C. (2008). Sonidos del silencio, voces silenciadas. Niños indígenas y migrantes en escuelas de Buenos Aires. Revista Mexicana de 
Investigación Educativa, 3, 173-201.

» Piña, C. (1988). La construcción del "sí mismo“ en el relato autobiográfico. Documento de trabajo, 383 (septiembre). Chile: Programa FLACSO-Chile.

» Saltalamacchia H. R., Colón, H. y Rodríguez, J. (1983). Historias de vida y movimientos sociales: propuestas para el uso de la técnica. Revista Iztapalapa, 9, 321-336.

»Santillán, L. (2008). Trayectorias educativas y cotidianeidad: Una etnografía del problema de la educación y la experiencia escolar en contextos de desigualdad. Buenos Aires: Propuesta Educativa.

» Santillán, L. (2011). ¿Quiénes educan a los chicos? Infancia, trayectorias educativas y desigualdad. Buenos Aires: Biblos.

"Sousa Santos, B. de (2010). Refundación del Estado en América Latina. Perspectivas desde una epistemología del Sur. Buenos Aires: Antropofagia.

» UNICEF (2011). Los pueblos indígenas en Argentina y el derecho a la educación. Situación socioeducativa de niñas, niños y adolescentes de comunidades toba. Argentina: Sattolo y Tenner.

\section{Otras fuentes consultadas}

» Censo del Bicentenario Resultados definitivos, Serie B № 2 Instituto Nacional de Estadística y Censos (INDEC) Buenos Aires (2010).

» Ley de Educación Nacional N²6.206 (2006).

» Ley de Educación de la Provincia del Chaco № 6691 (2010).

» Ley Provincial № 7446 de Educación Pública de Gestión Comunitaria Bilingüe Intercultural Indígena (2014). 